\title{
Remote estimation of carbon dioxide uptake by a Mediterranean forest
}

\author{
MARTÍN F. GARBULSKY*†, JOSEP PEÑUELAS*, DARIO PAPALE $\ddagger$ and \\ IOLANDA FILELLA* \\ *Unitat d'Ecofisiologia i Canvi Global, CSIC-CEAB-CREAF, CREAF (Centre de Recerca Ecologica i Aplicacions Forestals), \\ Edifici C, Universitat Autònoma de Barcelona, 08193 Bellaterra, Spain, $\dagger$ Faculty of Agronomy, University of Buenos Aires, \\ Av. San Martin 4453, C1417DSE, Buenos Aires, Argentina, †Department of Forest Science and Environment, University of Tuscia, \\ 01100 Viterbo, Italy
}

\begin{abstract}
The estimation of the carbon balance in ecosystems, regions, and the biosphere is currently one of the main concerns in the study of the ecology of global change. Current remote sensing methodologies for estimating gross primary productivity are not satisfactory because they rely too heavily on (i) the availability of climatic data, (ii) the definition of land-use cover, and (iii) the assumptions of the effects of these two factors on the radiation-use efficiency of vegetation (RUE). A new methodology is urgently needed that will actually assess RUE and overcome the problems associated with the capture of fluctuations in carbon absorption in space and over time. Remote sensing techniques such as the widely used reflectance vegetation indices (e.g. NDVI, EVI) allow green plant biomass and therefore plant photosynthetic capacity to be assessed. However, there are vegetation types, such as the Mediterranean forests, with a very low seasonality of these vegetation indices and a high seasonality of carbon uptake. In these cases it is important to detect how much of this capacity is actually realized, which is a much more challenging goal. The photochemical reflectance index (PRI) derived from freely available satellite information (MODIS sensor) presented for a 5-year analysis for a Mediterranean forest a positive relationship with the RUE. Thus, we show that it is possible to estimate RUE and GPP in real time and therefore actual carbon uptake of Mediterranean forests at ecosystem level using the PRI. This conceptual and technological advancement would avoid the need to rely on the sometimes unreliable maximum RUE.
\end{abstract}

Keywords: carbon cycle, $\mathrm{CO}_{2}$ uptake, eddy covariance, Mediterranean forests, MODIS, primary productivity, radiation use efficiency, remote sensing, vegetation

Received 21 January 2008 and accepted 26 April 2008

\section{Introduction}

The scientific community is devoting huge amounts of time and resources to assessing the global carbon budget in a context of climate change (Ciais et al., 2005; Boisvenue \& Running, 2006; Schulze, 2006). Current remote sensing methodologies for estimating gross primary productivity (GPP) mostly depend on absorbed radiation and the efficiency of conversion into

Correspondence: Martín F. Garbulsky, Unitat d'Ecofisiologia i Canvi Global, CSIC-CEAB-CREAF, CREAF (Centre de Recerca Ecològica i Aplicacions Forestals), Edifici C, Universitat Autònoma de Barcelona, 08193 Bellaterra, Spain, tel. + 0034 935813420, fax + 0034 935814151, e-mail: martin@creaf.uab.cat carbon-based compounds as proposed in Monteith's (1977) model. Most methodologies rely heavily on (i) the availability of climatic data, (ii) the definition of land-use cover to estimate the radiation-use efficiency of the vegetation (RUE) and/or (iii) assumptions of the effects of both these previous factors on the RUE. These methodologies are, thus dependent on the availability of climatic data, the quality of land-cover data, and assumptions regarding RUE (Heinsch et al., 2006).

Scientific work at leaf and plant scales reveals that it is possible to estimate radiation-use efficiency remotely by using a photochemical reflectance index (PRI) (Gamon et al., 1992; Peñuelas et al., 1995; Peñuelas et al., 1997). The PRI derived from a new breed of narrow-band spectroradiometers are increasingly being 
used as photosynthetic performance indicators at ecosystem level (Asner et al., 2004; Nakaji et al., 2006). By complementing the NDVI estimation of green biomass - and, therefore, of potential productivity (Gamon et al., 1995) - with PRI it is now possible to improve assessments from airborne sensors of the carbon uptake in many of the world's ecosystems (Rahman et al., 2001; Nichol et al., 2002, 2006). The global coverage of satellites has dramatically improved our capacity to extend PRI-based estimation of RUE and carbon fluxes to all areas of the globe. However, the highly interesting possibilities offered by satellite images are still little used and under evaluation (Rahman et al., 2004; Drolet et al., 2005). GPP estimations for ecosystems with low seasonality in their radiation absorption (e.g. evergreen forests) but high seasonality in their carbon absorption could especially benefit from this approach. In other ecosystems, where high seasonality in the leaf-area index is the main driver of carbon absorption, the traditional NDVI (Tucker et al., 1985) or EVI (Sims et al., 2006b) approach seems robust enough for arriving at a good estimation of the GPP (Sims et al., 2006a).

We evaluated the value of the PRI derived from satellite MODIS sensors as an estimator of the radiation-use efficiency for a Mediterranean forest in which (a) seasonal variation in radiation absorption (green biomass) is very low and (b) carbon absorption has important seasonal fluctuations that are mainly determined by water deficits during summer (Rambal et al., 2003) and low temperatures and incident radiation in winter (Ogaya \& Peñuelas, 2003), which provoke significant periods of very low photosynthesis. Because of the negligible changes in structure and leaf area index and thus in radiation absorption, it is of great importance in this forest to have accurate measurements of radiation-use efficiency. Thus, this forest study provides an ideal opportunity for exploring alternative methods of modelling carbon absorption employing satellite-based estimates of RUE.

\section{Materials and methods}

We analyzed eddy covariance data of carbon fluxes and MODIS (Moderate Resolution Imaging Spectroradiometer) remote sensing data for the period January 2001-December 2005 in the Mediterranean forests of Castelporziano in central Italy $\left(41^{\circ} 42^{\prime} 18.90^{\prime \prime}\right.$ latitude, $12^{\circ} 22^{\prime} 34.00^{\prime \prime}$ longitude). Climate is Mediterranean-type, with $828 \mathrm{~mm}$ mean annual rainfall over the sample period occurring mainly during autumn and winter. The mean annual temperature is $14.8^{\circ} \mathrm{C}$ for the same period. The vegetation is a $10 \mathrm{~m}$ tall broadleaf evergreen forest mainly dominated by holm oak (Quercus ilex) (Tirone et al., 2003) and a leaf area index of $3.5 \mathrm{~m}^{2} \mathrm{~m}^{-2}$ (Reichstein et al., 2002).
We used the PRI as a remotely sensed estimator of the RUE in the model proposed by Monteith (1977).

$$
\mathrm{GPP}=\mathrm{APAR} \times \mathrm{RUE},
$$

thus

$$
\text { RUE }=\text { GPP/APAR, }
$$

where RUE is the radiation-use efficiency, GPP is the GPP, and APAR is the PAR (incident photosynthetic active radiation) absorbed by the vegetation, as calculated by the product of PAR derived from the eddy covariance tower data and FPAR (the fraction of the PAR absorbed by the canopy). We evaluated three alternative estimators of the FPAR: the normalized difference vegetation index $[\mathrm{NDVI}=($ band $2-$ band 1$) /($ band $2+$ band 1$)]$, the enhanced vegetation index [EVI $=2.5$ (band $2-$ band 1 )/ (band $2+6 \times$ band $1-7.5 \times$ band 3 )], both derived from MODIS surface reflectance data [MOD09A1 band 1 (620$670 \mathrm{~nm})$, band $2(841-876 \mathrm{~nm})$, band $3(459-479 \mathrm{~nm})]$, and the MODIS FPAR product (MOD15A2) (Myneni et al., 2002). From NDVI and EVI data we calculated the FPAR as $\operatorname{FPAR}_{(\mathrm{NDVI})}=1.24 \times \mathrm{NDVI}-0.168$ (Sims et al., 2005) and $\mathrm{FPAR}_{(\mathrm{EVI})}=\mathrm{EVI}$ (Xiao et al., 2005).

The GPP was estimated from the total $\mathrm{CO}_{2}$ fluxes from the eddy covariance tower (Valentini et al., 2007). We used the current methodology to process the eddy covariance data: $\mathrm{CO}_{2}$ flux data was $\mathrm{u}^{*}$ filtered and ecosystem respiration and storage estimated (Reichstein et al., 2005; Papale et al., 2006) from climate data at 30-min resolution. We performed our analysis including and excluding the gap filled eddy covariance data (Reichstein et al., 2005), in order to reduce the uncertainty associated with gap filling errors produced by the Marginal Distribution Sampling methodology.

An average of the GPP and PAR half-hour values was used for days having MODIS surface reflectance data (MOD09A1). The MOD09A1 images consist of 8-day composites constructed from the daily surface reflectance for specific dates. The NDVI and the EVI were calculated from those images and assigned to those dates. We tested the correspondence between the daily and the 8-day GPP averages, and we found a high correlation between them $(r=0.93)$ and the slope of the relationship was not different from the $1: 1$ relationship, although the intercept was different $(P<0.001)$. Thus, the temporal resolution of the analysis is 8 days, which corresponds to that of the MOD09A1 and MOD15A2 data. Theoretically, this represents 46 periods per year; however, because of a lack of or a low quality of the remote sensing data or the tower data, we only obtained complete data for 32-39 periods per year. For all the MODIS data, quality flags were checked to discard low quality images. 
To calculate the PRI [PRI = (band 11-band 12) $/($ band 11 + band 12)], we extracted the MODIS daily-calibrated radiance (MODIS Terra L1b - MOD021KM V005) for bands $11(526-536 \mathrm{~nm})$ and $12(546-556 \mathrm{~nm})$ for the pixels (nominal $1 \mathrm{~km} \times 1 \mathrm{~km}$ ) that included the tower. Images were co-registered and we used the data of the $3 \times 3$ pixel window centered in the tower coordinates. By visual inspection of the images we also eliminated for the analysis the images that were not totally filtered by the MODIS cloud algorithm. We used for the calculation the same specific dates as for the NDVI and EVI calculations. Because the available MODIS surface reflectance data is not corrected for atmospheric effects for bands 11 and 12, we used the available calibrated radiances for those bands. The atmospheric effects on bands 11 and 12 are similar because they are positioned closely together in the spectrum (Vermote et al., 1997, 2002). Thus, we considered that a normalized spectral index, such as the PRI, would not be affected by using the calibrated radiances with or without atmospheric correction for its calculation. We evaluated the PRI as a seasonal estimator of the RUE [Eqn (2)] by linear and nonlinear correlations of the complete dataset. In order to test the stability of the model, we also evaluated the correlations for each of the 5 single years.

We estimated GPP based on Eqn (1) using PRI and FPAR $_{(M O D 15)}$ as surrogates for RUE and FPAR, respectively. To parameterize the relationship between PRI and RUE, we bootstrapped 30 times to generate different exponential models by random splitting the data into smaller datasets of the average sample size of a year $(n=23)$. To estimate RUE, we applied to the PRI data the average for the parameters of the 30 models. Finally, we compared the GPP from the eddy covariance tower against our final GPP estimates and the estimations regularly made by the MODIS team (Heinsch et al., 2003, MOD17A2, version 4.8). We evaluated both methodologies using PAR data estimated from incoming shortwave radiation derived from the global climate model for 2001-2004 [GEOS-4, Data Assimilation Office (DAO)] included in the MODIS GPP product.

\section{Results}

GPP ranged from 2 to $9 \mathrm{gC} \mathrm{m}^{-2}$ day $^{-1}$ (Fig. 1a), with minimum values occurring mainly in winter and local minima in summer. Radiation absorption, as estimated from NDVI, EVI and FPAR (MOD15), appeared very stable throughout the year (Fig. 1b). The RUE, estimated from tower PAR data and FPAR (MOD15) ranged between 0.3 and $2.2 \mathrm{~g} \mathrm{CMJ}^{-1}$. Minimum values occurred in summer and maximum values in winter or spring (Fig. 1c). The seasonality of the PRI was similar to that of the RUE

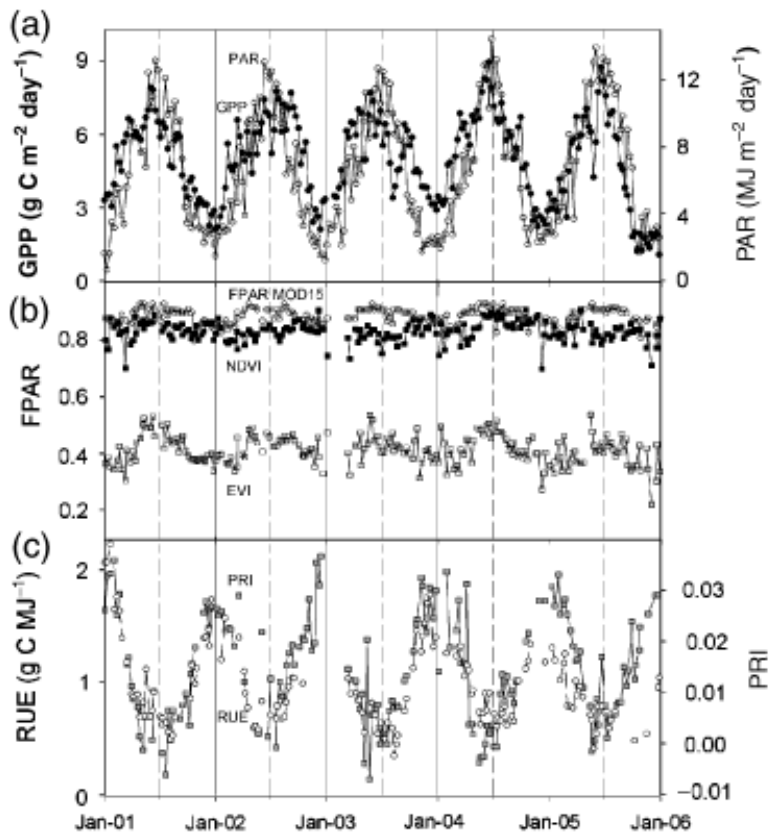

Fig. 1 Seasonal course of daily biophysical variables (20012005). (a) Gross primary productivity (GPP; open circles) and photosynthetic active radiation (PAR; black circles) derived from the eddy covariance tower, (b) seasonal dynamics of FPAR derived from: normalized difference vegetation index (NDVI; black squares), enhanced vegetation index (EVI; open squares), and FPAR(MOD15; open triangles) and (c) RUE estimated from FPAR $_{(M O D 15)}$ and PAR from the tower (circles) and photochemical reflectance index (PRI; gray squares).

throughout the study period. For most of the analyzed years, the PRI was a good reflection of seasonal changes in the timing and magnitude of RUE (Fig. 1c). However, a different scaling between RUE and PRI is evident for winter 2004-2005 and during the last months in 2005. During the last part of 2005 there was scarce RUE data because of the low reliability of the GPP coming from available eddy covariance data. The temporal coefficients of variation were higher for PRI (70\%) and RUE (43\%) than for the three estimators of FPAR (NDVI, EVI and MOD15) for the analyzed period $(4 \%, 14 \%$ and $3 \%$, respectively).

Incident PAR data derived from the tower and that from NASA DAO presented important differences $\left(\right.$ RMSE $=1.9 \mathrm{MJ} \mathrm{m}^{-2}$ day $\left.^{-1}\right)$. The most important differences occurred during the summer, when the tower PAR data were underestimated by the NASA DAO dataset (Fig. 2). On the contrary, values in the lower end of the gradient tend to be overestimated by the NASA DAO dataset.

The PRI presented significant linear and exponential relationships with RUE for the whole analyzed period. The exponential regression accounted for a slightly 


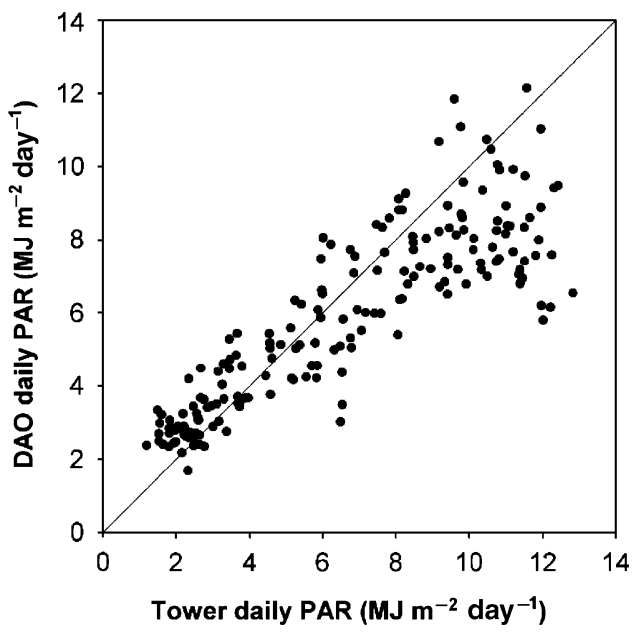

Fig. 2 Comparison of the 8-day mean incident radiation measured at the tower site and estimated by the global GEOS-4 model for the $1^{\circ}$ pixel in Castelporziano for 2001-2004.

greater proportion of the variability $(r=0.78)$ than the linear one $(r=0.76$; Fig. 3). The NDVI was not correlated with the RUE $(r=0.09)$ and the EVI presented a negative correlation with RUE $(r=-0.42)$. In order to reduce uncertainties associated with seasonal changes in incident radiation or the view zenith angle, we also tested the ability of the PRI to estimate the RUE splitting the data into high and low incident radiation (i.e. PAR $>7 \mathrm{MJ} \mathrm{m}^{-2}$ day $^{-1}$ or PAR $<7 \mathrm{MJ} \mathrm{m}^{-2}$ day $^{-1}$ ). For both cases, PRI positively correlated with RUE $(r=0.25, n=73$, $P<0.0001$ and $r=0.50, n=57, P<0.0001)$, and presented similar slopes $(P=0.51)$ but different intercepts $(P<0.001)$.

PRI and the RUE also presented positive relationships when analyzed for each single year. However, slopes and intercepts varied for certain years, regardless of whether RUE was estimated from NDVI or from EVI (data not shown). The strength of the relationships varied between years $(0.68<r<0.89)$. Also, the slopes of these relationships presented interannual variability, with lower values for 2004 and 2005 than those for the other three analyzed years. The slopes of these relationships were negatively correlated with the total annual precipitation for the period 2001-2005 $(r=-0.92 ; n=5$; $P<0.05)$.

The use of an exponential estimation of the RUE by means of the PRI for a subset of the data and the application of this relationship to the rest of the data together with DAO PAR data and FPAR $($ MOD15) strongly improved the MODIS NASA GPP estimate for 20012004 (Fig. 4). The use of PRI significantly reduced the error in the estimate of the 8-day GPP measured in the flux tower when compared with the MODIS NASA GPP product (MODIS17) based on the FPAR product and the

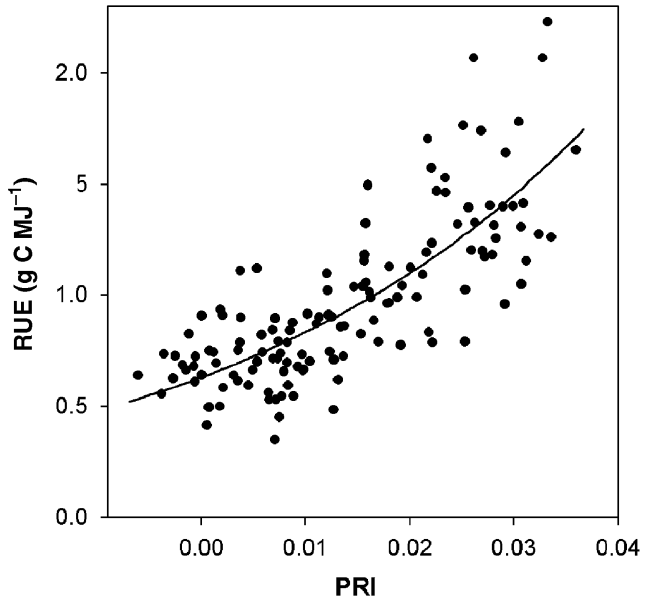

Fig. 3 Seasonal relationships between RUE and MODIS PRI for 2001-2005 $\left(r=0.78 ; P<0.0001 ;\right.$ RUE $=0.63 \mathrm{e}^{(27.76 \text { PRI })} ; F=205.58$; $n=131)$.

RUE estimate based on the maximum ecosystem RUE, the VPD, and the minimum temperature.

\section{Discussion}

In this study we provide evidence that the PRI is a reliable estimator of RUE at ecosystem level in Mediterranean forests. Therefore, a real time estimation of carbon uptake can be carried out at Mediterranean forests, and probably in other vegetation types with a low seasonality of leaf area change. Recent work showed that a model based on EVI and surface temperature worked well in many ecosystems, but not so well in a Mediterranean type ecosystem subjected to prolonged drought and large swings in RUE (Sims et al., 2007). The presented methodology relies on the basis of freely available remote sensing data that complements traditional well-established vegetation indices such as the EVI or the NDVI with the PRI. Our results may thus be of great importance and have multiple applications such as the estimation of the productivity $\left(\mathrm{CO}_{2}\right.$ fixation) of Mediterranean forests or the detection of the effects of climatic change on vegetation that may occur before leaf-area reduction. But these results provide not only a significant technological improvement but also an important conceptual advance because they show that optical signals incorporate information on vegetation physiological performance (photosynthetic rates linked to changes in pigment ratios) at an ecosystem scale. Our results warrant thus a generalized study of PRI performance in multiple ecosystems and conditions in order to confirm the high expectations raised by the results we present here. 


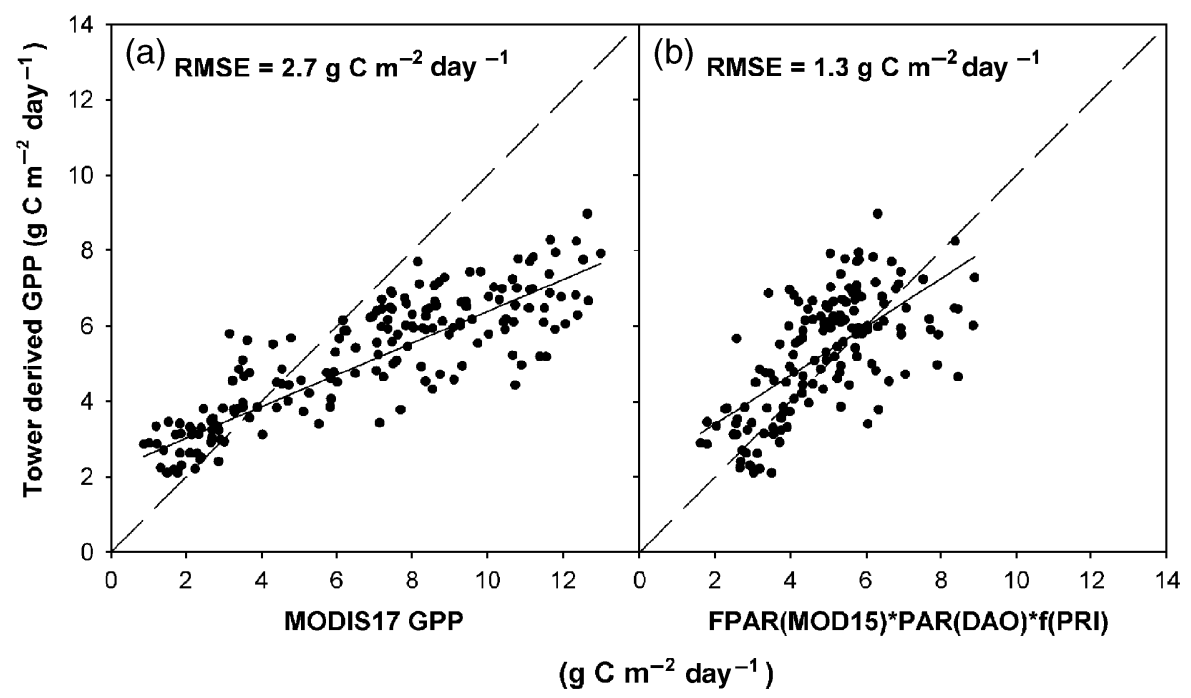

Fig. 4 Seasonal relationships between the daily GPP estimated from eddy covariance data and from remote sensing for 2001-2004. (a) MODIS17 GPP derived from FPAR $($ MOD15), climate data, and a RUE estimate based on the maximum ecosystem RUE, the VPD, and the

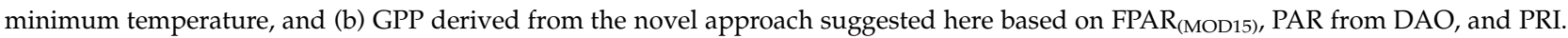
Black lines are the linear regression between datasets and dotted lines are the $1: 1$ relationships. Root mean square error (RMSE) is indicated for each estimation.

We tested the exponential and the linear PRI-RUE relationships. Both options were significant for the whole and the partial datasets. The coefficients of correlation in both types of models were similar for the 5 years dataset analysis, although the exponential regression accounted for a slightly greater proportion of the variability $(r=0.78)$ than the linear one $(r=0.76$; Fig. 3). The relationships also slightly varied for the different years. We presented the nonlinear model because the previous experimental studies at the leaf level showed a saturation of the PRI at high photosynthetic RUE values (e.g. Peñuelas et al., 1995; Gamon et al., 1997) more than linear relationships (e.g. Peñuelas et al., 1997; Nakaji et al., 2006). At the ecosystem level, the available scarce evidence showed linear relationships (e.g. Nichol et al., 2002; Drolet et al., 2005), although a low number of data points were included for much of those linear regression analyses.

We found that the PRI-RUE relationship varied between years and that this variation was partially explained by annual precipitation. There was a decrease in the slope for 2004 and 2005 that can be explained by a reduction in RUE due to lower GPP values during the winters 2004-2005 and 2005-2006, without a reduction in PRI. We hypothesize that this decrease in the slope could be partially explained by the lower respiration rates estimated from temperature and nighttime fluxes for those periods. The lower respiration rates could be a result of the particular climatic conditions of the year (Reichstein et al., 2002) or could also be due to the low quality of the GPP estimations in periods of high rainfall with possible underestimations of the ecosystem respiration. It would be of high interest to analyze databases for longer periods in the next future and to complement the eddy covariance measures with leaf level $\mathrm{CO}_{2}$ fluxes to rule out this kind of problems. Within years, the comparison of the PRI-RUE relationship showed stability of the slope between periods with low and high incident PAR, indicating that PRI is a good estimator of RUE independently of the seasonal changes in incident PAR.

The up-scaling of the previous work at leaf and plant level (Gamon et al., 1995; Peñuelas et al., 1995, 1997; Gamon \& Qiu, 1999) to the $1 \mathrm{~km} \times 1 \mathrm{~km}$ pixel level was successful for the studied Mediterranean forest, despite a number of a priori expected problems. Unlike greenness vegetation indices, which are mainly related to the red-edge reflectance of the vegetation, the PRI has a very low signal. Nevertheless, despite this low signal and the coarse spatial resolution of MODIS images, the PRI produced a very accurate signal of RUE presumably based on a leaf-level process related to the dissipation of radiation excess by plants and consequent xanthophyll pigment epoxidation. It is also likely that PRI scales with seasonal pigment changes (e.g. carotenoids/chlorophyll a ratio) and other related photosynthetic processes with stronger signals (Sims \& Gamon, 2002; Filella et al., 2004). Further studies are warranted to improve our understanding of which of these possibilities (xanthophylls cycle or pigment ratios) are 
primarily driving the seasonal changes in the MODIS PRI signal.

A second possible problem relates to the temporal matching between data from the carbon flux and the satellite spectral data. The MODIS Terra platform passes over in the morning and thus may not capture the full day gas exchange performance. For example, it may miss the afternoon decrease in carbon uptake as a result of summer drought. However, previous work in Mediterranean ecosystems suggest that seasonal downregulation of carbon absorption due to chronic moisture or temperature stress is perhaps more significant than diurnal patterns (Xu \& Baldocchi, 2004; Allard et al., 2008), thus the morning overpasses used here should work fine as seasonal indicators of RUE. In any case, it would be interesting to address, by means of experimental tests, the importance of the time of the day for reflectance measurements to estimate PRI at ecosystem scales.

Furthermore, there are still a number of problems regarding the use of this data, above all associated with computational difficulties when performing atmospheric corrections. Corrected reflectances from MODIS are available only for seven out of its 36 bands, and the corrected data for constructing narrow-band spectral indexes such as the PRI are not available yet. Our data suggests that this problem can be overcome by using a normalized reflectance index, PRI, based on spectral bands closely located in the green portion of the electromagnetic spectrum, in order to make correction unnecessary. Therefore, this fact makes the data and the calculations available for everybody by accessing the MODIS data webpage. Previous work (Drolet et al., 2005) also provides evidence that atmospheric correction for close wavelengths is not always necessary.

A fourth issue is that the consistent relationship between ground and satellite data was found despite the fact that soil and plant respiration may produce a significant scatter in the relationship between PRI and carbon uptake. This is due to the fact that while PRI tracks gross photosynthesis (i.e. direct carbon uptake not including respiratory loss), conventional flux sampling methods provide the net $\mathrm{CO}_{2}$ flux (i.e. combined photosynthetic carbon gain and respiratory loss) from the sampling area and ecosystem respiration is estimated from environmental variables (temperature and water availability) and extrapolation of night-time values of ecosystem respiration into the daytime (Reichstein et al., 2005).

Another issue is related to georegistration problems and to the low spatial resolution of the MODIS PRI. The use of a high number of images with the possible lack of coregistration between them is a problem when comparing a single pixel with the tower data. To reduce the noise derived from these problems we used a large enough Mediterranean forest site $\left(>2.5 \mathrm{~km}^{2}\right)$ to get the reflectance signal with a $1 \mathrm{~km}^{2}$ MODIS pixel. These problems would be reduced using higher spatial resolution data, from present satellites and those coming in the future.

Finally, there are also the confounding physical effects of canopy structure, leaf movement, sun angle, and soil background that may also significantly influence the PRI signal (Gamon et al., 1992). Areas with low vegetation cover would present problems when using this methodology (Filella et al., 2004; Sims et al., 2006a). The higher leaf area index in Castelporziano compared with other Mediterranean forests could account for the higher strength of the relationship between PRI and RUE in this site. Moreover, the strong PRI-RUE relationship in this closed-canopy stand is also supported by previous studies that experimentally showed for a diversity of closed-canopy stands the close relationship of stand-level PRI with leaf level PRI (Gamon \& Qiu, 1999).

In any case, it is necessary to check our results in other homogeneous Mediterranean forests larger enough to place the MODIS $1 \mathrm{~km}^{2}$ pixel, and to examine a range of ecosystems to reveal whether the utility of the PRI to assess carbon uptake will vary with the ecosystem in question due to contrasting environmental constraints, ecophysiological strategies, and light-use efficiencies. A comprehension of ecophysiological principles will be needed to fully reveal these patterns and it is likely that new remote-sensing approaches incorporating PRI will contribute to this understanding.

\section{Acknowledgements}

M. F. G. was supported by the University of Buenos Aires, the Commissioner for Universities and Research of the Ministry of Innovation, Universities and Enterprise of the Catalan Government and of the European Social Fund and the Alßan Programme. This work was funded under grants from the Catalan Government (SGR2005-00312), and the Spanish Ministry of Education and Science (CGL2006-04025/BOS). X. Pons and one anonymous reviewer provided helpful comments to improve the quality of the manuscript.

\section{References}

Allard V, Ourcival JM, Rambal S, Joffre R, Rocheteau A (2008) Seasonal and annual variation of carbon exchange in an evergreen Mediterranean forest in Southern France. Global Change Biology, 14, 714-725.

Asner GP, Nepstad D, Cardinot G, Ray D (2004) Drought stress and carbon uptake in an Amazon forest measured with spaceborne imaging spectroscopy. Proceedings of the National Academy of Sciences of the United States of America, 101, 6039-6044. 
Boisvenue C, Running SW (2006) Impacts of climate change on natural forest productivity - evidence since the middle of the 20th century. Global Change Biology, 12, 862.

Ciais P, Reichstein M, Viovy N et al. (2005) Europe-wide reduction in primary productivity caused by the heat and drought in 2003. Nature, $437,529-533$

Drolet GG, Huemmrich KF, Hall FG, Middleton EM, Black TA, Barr AG, Margolis HA (2005) A MODIS-derived photochemical reflectance index to detect inter-annual variations in the photosynthetic light-use efficiency of a boreal deciduous forest. Remote Sensing of Environment, 98, 212-224.

Filella I, Peñuelas J, Llorens L, Estiarte M (2004) Reflectance assessment of seasonal and annual changes in biomass and $\mathrm{CO}_{2}$ uptake of a Mediterranean shrubland submitted to experimental warming and drought. Remote Sensing of Environment, 90, 308-318.

Gamon JA, Field CB, Goulden M et al. (1995) Relationships between NDVI, canopy structure, and photosynthetic activity in three Californian vegetation types. Ecological Applications, 5, 28-41.

Gamon JA, Peñuelas J, Field CB (1992) A narrow-waveband spectral index that tracks diurnal changes in photosynthetic efficiency. Remote Sensing of Environment, 41, 35-44.

Gamon JA, Qiu H-L (1999) Ecological applications of remote sensing at multiple scales. In: Handbook of Functional Plant Ecology (eds Pugnaire FI, Valladares F), pp. 805-846. Marcel Dekker Inc., New York.

Gamon JA, Serrano L, Surfus JS (1997) The photochemical reflectance index: an optical indicator of photosynthetic radiation use efficiency across species, functional types, and nutrient levels. Oecologia, 112, 492-501.

Heinsch FA, Reeves M, Votava P et al. (2003) User's Guide GPP and NPP (MOD17A2/A3) Products NASA MODIS Land Algorithm. University of Montana, Missoula, MT.

Heinsch FA, Zhao M, Running SW et al. (2006) Evaluation of remote sensing based terrestrial productivity from MODIS using regional tower eddy flux network observations. IEEE Transactions on Geoscience and Remote Sensing, 44, 1908-1925.

Monteith JL (1977) Climate and the efficiency of crop production in Britain. Philosophical Transactions of the Royal Society B: Biological Sciences, 281, 277-294.

Myneni RB, Hoffman S, Knyazikhin Y et al. (2002) Global products of vegetation leaf area and fraction absorbed PAR from year one of MODIS data. Remote Sensing of Environment, 83, 214-231

Nakaji T, Oguma H, Fujinuma Y (2006) Seasonal changes in the relationship between photochemical reflectance index and photosynthetic light use efficiency of Japanese larch needles. International Journal of Remote Sensing, 27, 493-509.

Nichol CJ, Lloyd J, Shibistova O et al. (2002) Remote sensing of photosynthetic-light-use efficiency of a Siberian boreal forest. Tellus Series B: Chemical and Physical Meteorology, 54, 677-687.

Nichol CJ, Rascher U, Matsubara S, Osmond B (2006) Assessing photosynthetic efficiency in an experimental mangrove canopy using remote sensing and chlorophyll fluorescence. TreesStructure and Function, 20, 9-15.

Ogaya R, Peñuelas J (2003) Comparative field study of Quercus ilex and Phillyrea latifolia: photosynthetic response to experi- mental drought conditions. Environmental and Experimental Botany, 50, 137-148.

Papale D, Reichstein M, Aubinet M et al. (2006) Towards a standardized processing of Net Ecosystem Exchange measured with eddy covariance technique: algorithms and uncertainty estimation. Biogeosciences, 3, 571-583.

Peñuelas J, Filella I, Gamon JA (1995) Assessment of photosynthetic radiation-use efficiency with spectral reflectance. New Phytologist, 131, 291-296.

Peñuelas J, Llusia J, Piñol J, Filella I (1997) Photochemical reflectance index and leaf photosynthetic radiation-useefficiency assessment in Mediterranean trees. International Journal of Remote Sensing, 18, 2863-2868.

Rahman AF, Cordova VD, Gamon JA, Schmid HP, Sims DA (2004) Potential of MODIS ocean bands for estimating $\mathrm{CO}_{2}$ flux from terrestrial vegetation: A novel approach. Geophysical Research Letters, 31, L10503, doi: 10.1029/2004GL019778.

Rahman AF, Gamon JA, Fuentes DA, Roberts DA, Prentiss D (2001) Modeling spatially distributed ecosystem flux of boreal forest using hyperspectral indices from AVIRIS imagery. Journal of Geophysical Research [Atmospheres], 106, 33579-33591.

Rambal S, Ourcival J-M, Joffre R, Mouillot F, Nouvellon Y, Reichstein M, Rocheteau A (2003) Drought controls over conductance and assimilation of a Mediterranean evergreen ecosystem: scaling from leaf to canopy. Global Change Biology, 9, 1813-1824.

Reichstein M, Falge E, Baldocchi D et al. (2005) On the separation of net ecosystem exchange into assimilation and ecosystem respiration: review and improved algorithm. Global Change Biology, 11, 1424-1439.

Reichstein M, Tenhunen JD, Roupsard O, Ourcival JM, Rambal S, Dore S, Valentini R (2002) Ecosystem respiration in two Mediterranean evergreen Holm Oak forests: drought effects and decomposition dynamics. Functional Ecology, 16, 27-39.

Schulze ED (2006) Biological control of the terrestrial carbon sink. Biogeosciences, 3, 147-166.

Sims DA, Gamon JA (2002) Relationships between leaf pigment content and spectral reflectance across a wide range of species, leaf structures and developmental stages. Remote Sensing of Environment, 81, 337-354.

Sims DA, Luo H, Hastings S, Oechel WC, Rahman AF, Gamon JA (2006a) Parallel adjustments in vegetation greenness and ecosystem $\mathrm{CO}_{2}$ exchange in response to drought in a Southern California chaparral ecosystem. Remote Sensing of Environment, 103, 289-303.

Sims DA, Rahman AF, Cordova VD et al. (2005) Midday values of gross $\mathrm{CO}_{2}$ flux and light use efficiency during satellite overpasses can be used to directly estimate eight-day mean flux. Agricultural and Forest Meteorology, 131, 1-12.

Sims DA, Rahman AF, Cordova VD et al. (2006b) On the use of MODIS EVI to assess gross primary productivity of North American ecosystems. Journal of Geophysical Research-Biogeosciences, 111, G04015, doi: 10.1029/2006JG000162.

Sims DA, Rahman AF, Cordova VD et al. (2007) A new model of gross primary productivity for North American ecosystems based solely on the enhanced vegetation index and land 
surface temperature from MODIS. Remote Sensing of Environment, 112, 1633-1646.

Tirone G, Dore S, Matteucci G, Greco S, Valentini R (2003) Evergreen Mediterranean Forests: carbon and water fluxes, balances, ecological and ecophysiological determinants. In: Fluxes of Carbon, Water and Energy of European Forests. Ecological Studies 163 (ed. Valentini R), pp. 125-150. Springer, Berlin.

Tucker CJ, Vanpraet CL, Sharman MJ, Vanittersum G (1985) Satellite Remote-Sensing of Total Herbaceous Biomass Production in the Senegalese Sahel - 1980-1984. Remote Sensing of Environment, 17, 233-249.

Valentini R, Arriga N, Mazzenga F, Stefani P (2007) Level 4 dataset CEIP_EC_L4_ITCpz_v01 in CarboeuropeIP Ecosystem Component Database, http://gaia.agraria.unitus.it/database
Vermote EF, El Saleous NZ, Justice CO (2002) Atmospheric correction of MODIS data in the visible to middle infrared: first results. Remote Sensing of Environment, 83, 97-111.

Vermote EF, Tanré D, Deuzé JL, Herman M, Morcrette JJ (1997) Second simulation of the satellite signal in the solar spectrum, 6S: an overview. IEEE Transactions on Geoscience and Remote Sensing, 35, 675-686.

Xiao XM, Zhang QY, Hollinger D, Aber J, Moore B (2005) Modeling gross primary production of an evergreen needleleaf forest using MODIS and climate data. Ecological Applications, 15, 954-969.

Xu LK, Baldocchi DD (2004) Seasonal variation in carbon dioxide exchange over a Mediterranean annual grassland in California. Agricultural and Forest Meteorology, 123, 79-96. 